\title{
Characterization and Quantitation of a Zinc- Binding Ligand in Human Milk
}

\author{
GARY W. EVANS ${ }^{(20)}$ AND PHYLLIS E. JOHNSON \\ United States Department of Agriculture, Science and Education Administration, Human Nutrition Laboratory, Grand \\ Forks, North Dakota, USA
}

\begin{abstract}
Summary
A low-molecular-weight zinc-binding ligand from human milk has been isolated and characterized. The ligand was isolated by chromatography on Dowex 50, Dowex 1, and Sephadex G-15 equilibrated with $0.153 \mathrm{mM} \mathrm{Zn}\left(\mathrm{NO}_{3}\right)_{2}$. Mass spectroscopy, thinlayer chromatography, and infrared spectroscopy proved that the zinc-binding ligand isolated by this method from human milk is pyridine-2-carboxylic acid, commonly known as picolinic acid. The concentration of picolinic acid in human milk was $308 \mu \mathrm{M}$, the concentration in one brand of processed cow's milk was $20 \mu \mathrm{M}$, but picolinic acid was undetectable in a second brand of cow's milk and in four different infant formulas. Weanling rats fed supplemental picolinic acid absorbed significantly more dietary zinc and gained significantly more weight than rats fed an unsupplemented diet. The results suggest that the high bioavailability of zinc in human milk results from the presence of picolinic acid, a bidentate chelating ligand which facilitates zinc absorption from the intestine.
\end{abstract}

\section{Speculation}

The high bioavailability of zinc in human milk results from the presence of picolinic acid, a bidentate chelating ligand which facilitates zinc absorption from the intestine.

Several clinical observations demonstrate that the bioavailability of zinc from human milk is much greater than that from cow's milk. In children affected with acrodermatitis enteropathica, an inherited disease that affects zinc metabolism (8), the symptoms characteristic of the disease do not generally appear until the child is weaned from the breast $(1,4,5)$. Human milk has also been used successfully in the treatment of acrodermatitis enteropathica (15). Hambidge et al. (9) found that the plasma zinc concentration of breast-fed infants is not significantly different than that of healthy young adults. In contrast, the plasma zinc concentration of infants fed either zinc-supplemented formula or non-zinc-supplemented formula is significantly less than that of young adults. These observations suggest that human milk may contain a ligand or ligands which facilitate zinc absorption.

To date, attempts to isolate zinc-binding ligands from biologic fluids have not been successful due to the fact that investigators have consistently used classical gel filtration chromatography. The problems encountered when attempting to detect and identify zinc-chelating ligands by the use of classical gel filtration have been discussed by Evans et al: (6). These authors have also described a technique, referred to as modified gel filtration chromatography, which can be used to reproducibly detect zinc-binding ligands in biologic fluids. This technique has now been adapted to isolate and quantitate a zinc-binding ligand in human milk.

\section{MATERIALS AND METHODS}

\section{DETECTION OF ZINC-BINDING LIGANDS}

The presence or absence of zinc-binding ligands in the fractions recovered during purification was determined by the use of mod- ified gel filtration chromatography. A glass column $1.5 \times 90 \mathrm{~cm}$ was packed with $44.4 \mathrm{~g}$ Sephadex G-15 (Pharmacia Fine Chemi cals, Inc.) (18). The gel was equilibrated with $50 \mathrm{mM}$ Tris acetate $\mathrm{pH} 7.4$, that contained $0.1 \% \mathrm{NaN}_{3}$ and $0.153 \mathrm{mM} \mathrm{Zn}\left(\mathrm{NO}_{3}\right)_{2}$. Th buffer was run through the gel until the zinc concentration of the eluted fractions was equal to the zinc concentration of the equili. brating buffer, $10 \mu \mathrm{g}$ zinc per $\mathrm{ml}$.

Freeze-dried fractions obtained during purification were firs dissolved in $2 \mathrm{ml}$ of the Tris buffer described above. Wher necessary, the solution was adjusted to $\mathrm{pH} 7.4$ with $\mathrm{LiOH}$. The solution was then applied to the gel and eluted with the zinc containing Tris buffer. Fractions of $0.8 \mathrm{ml}$ were collected anc assayed for zinc content by the use of atomic absorption spectrom etry (Varian model 1250).

\section{PREPARATION OF MILK ULTRAFILTRATES}

Breast milk was obtained from nursing mothers within 2 w after parturition. The milk was collected by hand expression int acid-washed containers and was stored frozen until used.

The milk was first centrifuged at $27,000 \times g$ for $20 \mathrm{~min}$ in refrigerated centrifuge after which the layer of fat was decantec from the top of the supernatant. The supernatant was then filterec through Whatman No. 1 filter paper in a Buchner funnel.

Ultrafiltrates were prepared by subjecting the filtered superna tants to ultrafiltration under $\mathrm{N}_{2}$ at $60 \mathrm{psi}$ in an Amicon Ultrafil tration Cell equipped with an Amicon XM-50 membrane (exclu sion limit $=50,000$ daltons). The ultrafiltrates were then filtere under $\mathrm{N}_{2}$ at 60 psi in an Amicon Ultrafiltration Cell equippe with an Amicon UM-10 membrane (exclusion limit $=10,00$ daltons). The ultrafiltrates were freeze-dried after which the solic material was weighed and redissolved in deionized water to yiel a solution that contained $200 \mathrm{mg} / \mathrm{ml}$. The solution was ther divided into $5 \mathrm{ml}$ aliquots which were stored frozen until used.

\section{CHROMATOGRAPHY ON CATION-EXCHANGE RESIN}

A 5-ml aliquot of the ultrafiltrate was first chromatographed or a cation exchange resin. The sample was applied to a $0.9-\times 13$ cm column packed with Dowex 50W (Sigma Chemical Co.) i the hydrogen ion form. The sample was eluted with deionize water, and the eluted fractions were monitored with an LKI Uvicord II set at $254 \mathrm{~nm}$. The ultraviolet-detectable fraction eluted from Dowex 50 were freeze-dried and thereafter chromat ographed on Sephadex G-15.

\section{CHROMATOGRAPHY ON ANION-EXCHANGE RESIN}

A 5-ml aliquot of the milk ultrafiltrate preparation was firs chromatographed on Dowex 50 as described above. Thereafter the fractions which were known to contain the zinc-binding ligan were pooled and applied directly to a $0.9-\times 5-\mathrm{cm}$ column o Dowex 1 (Sigma Chemical Co.) in the formate form. After th sample had been applied, the column was washed first with $30 \mathrm{~m}$ deionized water, followed by $50 \mathrm{ml} 0.05 \mathrm{M}$ formic acid, and finally with $30 \mathrm{ml} 0.5 \mathrm{M}$ formic acid. The eluted fractions were monitorec 
at $254 \mathrm{~nm}$, and the ultraviolet-detectable fractions were pooled, freeze-dried, and chromatographed on Sephadex G-15.

\section{PURIFICATION OF THE ZINC-BINDING LIGAND}

A 5-ml aliquot of the milk ultrafiltrate preparation was chromatographed on Dowex 50 and Dowex 1 as described above. Thereafter, the freeze-dried fractions recovered from Dowex 1 that contained the zinc-binding ligand were dissolved in $2.5 \mathrm{ml}$ deionized water that contained $0.153 \mathrm{mM} \mathrm{Zn}\left(\mathrm{NO}_{3}\right)_{2}$. The solution was then applied to a $1.6-\times 110-\mathrm{cm}$ column packed with Sephadex $\mathrm{G}-15$ that had been equilibrated with $0.153 \mathrm{mM} \mathrm{Zn}\left(\mathrm{NO}_{3}\right)_{2}$. The applied sample was eluted from the column with $0.153 \mathrm{mM}$ $\mathrm{Zn}\left(\mathrm{NO}_{3}\right)_{2}$. Fractions of $1.0 \mathrm{ml}$ were collected and subsequently diluted with $9.0 \mathrm{ml}$ deionized water. The diluted fractions were then assayed for zinc content by atomic absorption spectrometry. Those fractions which comprised a zinc peak were pooled and freeze-dried for analysis by mass spectrometry, thin-layer chromatography, and infrared spectroscopy.

\section{MASS SPECTROMETRY}

Mass spectra of solid samples were determined with a DuPont model 21-491 B mass spectrometer at a source temperature of $300^{\circ} \mathrm{C}$ and an electron energy of $70 \mathrm{eV}$.

\section{THIN-LAYER CHROMATOGRAPHY}

Ascending thin-layer chromatography was carried out on Gelman ITLC-SA sheets (Gelman Instrument Co.) that had been activated at $110^{\circ} \mathrm{C}$ for $1.5 \mathrm{hr}$. After sample application, the sheets were equilibrated for $15 \mathrm{~min}$ in the chromatography tank filled with solvent. Three different solvents were used for chromatography: butanol:acetic acid:water, 4:1:2; butanol saturated with 2.5 $\mathrm{M} \mathrm{NH} \mathrm{H}_{4} \mathrm{OH}$; and $80 \%$ isopropanol. Organic substances were detected with a Mineralight UVSL-25 ultraviolet lamp (Ultra-Violet Products Inc., San Gabriel, CA).

\section{INFRARED SPECTROSCOPY}

The infrared spectra of known and unknown compounds in $\mathrm{KBr}$ pellets were determined with a Perkin Elmer model 467 grating spectrophotometer.

\section{QUANTITATION OF THE ZINC-BINDING LIGAND IN HUMAN AND COW'S MILK}

Ultrafiltrates were prepared as described above from $10 \mathrm{ml}$ pooled human milk ( 5 separate donors), from $20 \mathrm{ml}$ each of two different brands of processed cow's milk (Minnesota Dairy and Bridgeman Dairies), and from $20 \mathrm{ml}$ each of four different brands of infant formula (Similac, Ross Laboratories; Isomil, Ross Laboratories; SMA, Wyeth Laboratories; Enfamil, Mead Johnson Laboratories). Each of the ultrafiltrates was chromatographed sequentially on Dowex 50, Dowex 1, and Sephadex G-15 as described above. Those fractions recovered from Sephadex G-15 that contained the zinc-binding ligand were pooled and freezedried.

The freeze-dried fractions from each preparation were first dissolved in $1.9 \mathrm{ml}$ deionized water. Thereafter, $0.1 \mathrm{ml} 0.1 \mathrm{~N} \mathrm{HCl}$ was added to the solution, and the absorbance at $265 \mathrm{~nm}$ was determined with a Beckman DB-GT spectrophotometer. The quantity of zinc-binding ligand (picolinic acid) was calculated from the molar extinction coefficient of picolinic acid (Sigma Chemical Co.) in $5 \mathrm{mM} \mathrm{HCl}$.

\section{DETERMINATION OF ZINC ABSORPTION IN RATS FED PICOLINIC ACID}

To determine the effect of picolinic acid on zinc absorption, male weanling Long-Evans rats were divided into four groups of six rats each. The rats were maintained in suspended stainless steel cages and were given free access to deionized water and diet. The rats were fed a basal diet similar to that described by Evans et al. (7), but the diet was formulated with $20 \%$ vitamin-free casein rather than egg white, and biotin was omitted. The zinc content of the diet was $16.5 \mu \mathrm{g}$ zinc per g. Six rats (group 1) were fed the basal diet, six rats (group 2) were fed the basal diet supplemented with $0.2 \mathrm{mg}$ picolinic acid per g, six rats (group 3) were fed the basal diet supplemented with $2 \mathrm{mg}$ DL-methionine per $\mathrm{g}$, and six rats (group 4) were fed the basal diet supplemented with $2 \mathrm{mg}$ DLmethionine per $\mathrm{g}$ and $0.2 \mathrm{mg}$ picolinic acid per $\mathrm{g}$.

After the rats had been fed the diets for four wk, each animal was given an im (left thigh) injection of $10 \mu \mathrm{Ci}$ carrier-free ${ }^{65} \mathrm{Zn}$ (New England Nuclear) in $0.1 \mathrm{ml}$ saline solution. Nine days later, food consumption was measured while urine and feces were collected quantitively for a 5-day period. The true, total daily absorption of dietary zinc was determined by use of an isotope dilution technique (7).

\section{RESULTS}

\section{DETECTION OF THE ZINC-BINDING LIGAND}

As shown in Figure 1, when ultrafiltrates from either the Amicon XM-50 membrane or the UM-10 membrane were chromatographed on Sephadex G-15, identical results were obtained. With each of these ultrafiltrates, zinc was recovered in fractions that comprised one peak at $\mathrm{V}_{\mathrm{e}} / \mathrm{V}_{\mathrm{o}}=1.61$ and a second, broad peak was recovered at $\mathrm{V}_{\mathrm{e}} / \mathrm{V}_{\mathrm{o}}=1.95$.

Chromatography of the human milk ultrafiltrates on Dowex 50 resin resulted in the emergence of one major ultraviolet-detectable fraction and several minor UV-detectable fractions (Figure 2A). When each of the UV-detectable fractions was chromatographed on Sephadex G-15, neither Fraction 2 nor Fraction 3 produced any change in the normal elution of zinc from the equilibrated column. However, when Fraction 1 from Dowex 50 was chromatographed on Sephadex G-15, zinc was recovered in tubes that comprised one peak at $\mathrm{V}_{\mathrm{e}} / \mathrm{V}_{\mathrm{o}}=1.61$ and a second peak at $\mathrm{V}_{\mathrm{e}} / \mathrm{V}_{\mathrm{o}}$ $=1.95$ (Figure $3 A)$.

We have observed that cations such as potassium, sodium, and calcium present in human milk displace zinc from binding sites on the zinc-equilibrated gels (6). Furthermore, these cations result in the elution of zinc in fractions from $\mathrm{V}_{\mathrm{e}} / \mathrm{V}_{\mathrm{o}}=1.75$ to $\mathrm{V}_{\mathrm{e}} / \mathrm{V}_{\mathrm{o}}=$ 1.95. Thus, the marked reduction in the quantity of zinc recovered

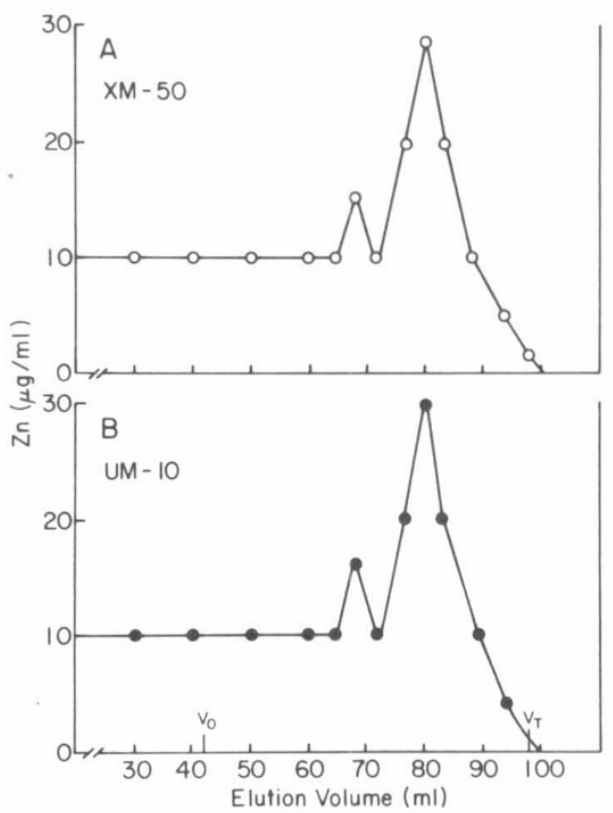

Fig. 1. Chromatography of human milk ultrafiltrates on Sephadex G15 equilibrated with a zinc-containing buffer. $A, 100 \mathrm{mg}$ human milk ultrafiltrate recovered from Amicon XM-50 membrane; $B, 100 \mathrm{mg}$ human milk ultrafiltrate recovered from Amicon UM 10 membrane. Flow rate $=0.5 \mathrm{ml} / \mathrm{min} ; V_{o}=$ void volume determined with Blue Dextran (Pharmacia Fine Chemicals), $V_{T}=$ elution volume of tritiated water (Packard). For details, see text. 


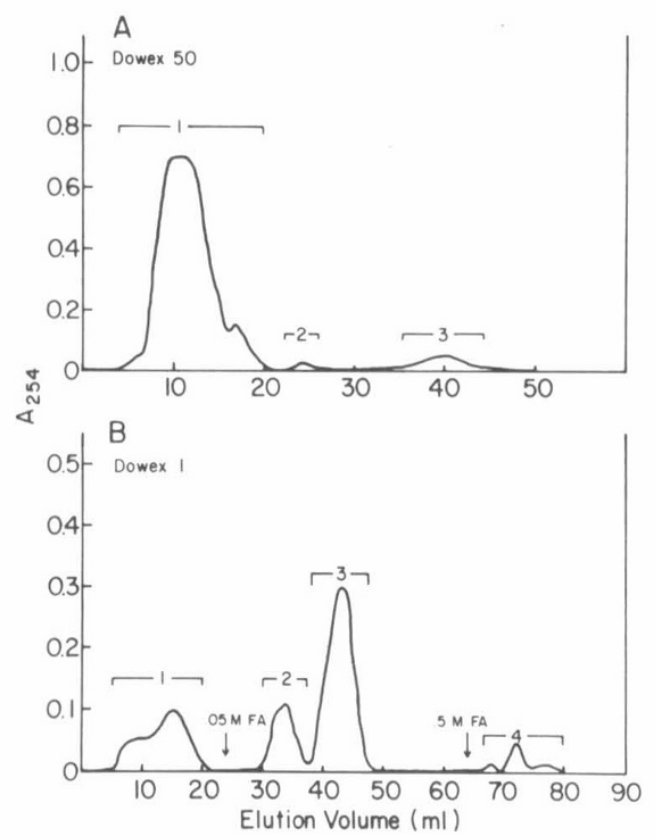

Fig. 2. Elution of ultraviolet-detectable fractions from human milk ultrafiltrates chromatographed on ion-exchange resins. $A, 1.0 \mathrm{~g}$ ultrafiltrate from Amicon UM 10 chromatographed on Dowex 50 in the hydrogen ion form; $B$, Fraction 1 from Dowex 50 chromatographed on column of Dowex 1 in the formate form. Flow rate $=0.5 \mathrm{ml} / \mathrm{min} ; F A=$ formic acid.

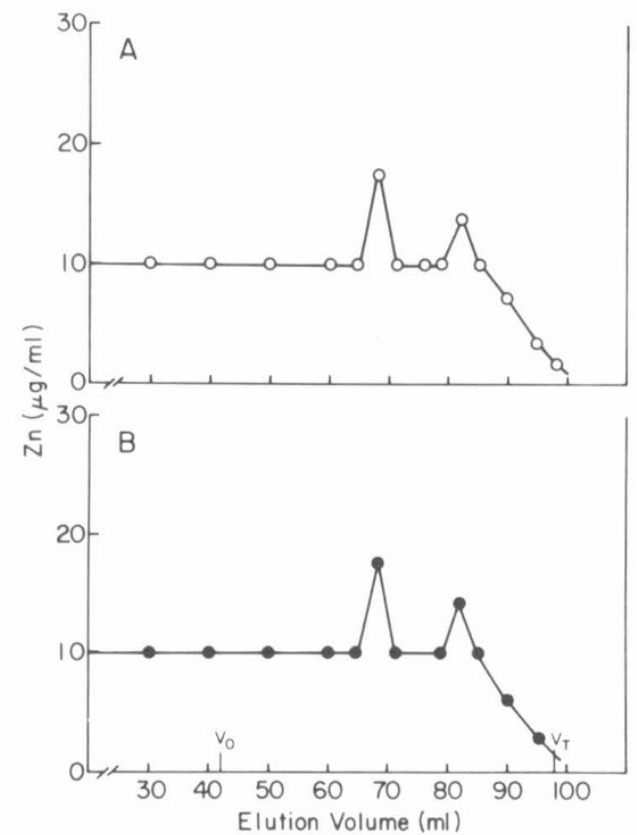

Fig. 3. Chromatography of ultraviolet-detectable fractions from ionexchange resins on Sephadex G-15 equilibrated with a zinc-containing buffer. $A$, Fraction 1 from Dowex 50 (see Fig. 2); $B$, Fraction 2 from Dowex 1 (see Fig. 2).

in the second fraction $\left(V_{e} / V_{o}=1.95\right)$ off Sephadex $G-15$ results from the removal of these cations after chromatography on Dowex 50 .

When Fraction 1 from Dowex 50 was chromatographed on Dowex 1 by the use of a step gradient, 4 UV-detectable fractions were eluted (Fig. $2 B$ ). One fraction was recovered with the water rinse. This fraction contained no zinc-binding ligand but gave a strong positive test when mixed with anthrone reagent. Thus, Fraction 1 from Dowex 1 contained lactose, the major contaminant in the ultrafiltrate preparations.
Two ultraviolet-detectable fractions (Fractions 2 and 3) were eluted from Dowex 1 following the application of $0.05 \mathrm{M}$ formic acid. As illustrated in Figure $3 B$, Fraction 2 contained the zincbinding ligand. Analysis of Fraction 3 by thin-layer chromatography proved that this fraction contained primarily nicotinic acid.

\section{PURIFICATION AND CHARACTERIZATION}

After the elution profile of the zinc-binding ligand was determined on the ion-exchange resins, aliquots of human milk ultrafiltrate were purified by chromatography on Dowex 50, Dowex 1 , and Sephadex G-15 that had been equilibrated with $0.153 \mathrm{mM}$ $\mathrm{Zn}\left(\mathrm{NO}_{3}\right)_{2}$ in deionized water. As shown in Figure 4, this purification technique resulted in the recovery of zinc in two fractions, $\mathrm{V}_{\mathrm{e}} / \mathrm{V}_{\mathrm{o}}=1.61$ and $\mathrm{V}_{\mathrm{e}} / \mathrm{V}_{\mathrm{o}}=1.95$.

\section{MASS SPECTRAL ANALYSIS}

The parent peak and fragmentation profiles obtained after mass spectral analysis of Fractions 1 and 2 from Sephadex G-15 (Fig. 4) indicated that the zinc in these fractions was chelated by the same ligand. Fraction 1 contained a complex consisting of zinc coordinated with two ligand molecules, $\mathrm{ML}_{2}$, whereas Fraction 2 contained zinc coordinated with one ligand molecule, ML.

As shown in Figure 5, the mass spectrum of the zinc-binding ligand from human milk was identical to that of a picolinic acidzinc complex. Both spectra contained a molecular ion peak at $\mathrm{m} /$ $e 308$ with an isotope peak at $m / e 310$. These peaks correspond to the complex containing ${ }^{64} \mathrm{Zn}$ and ${ }^{66} \mathrm{Zn}$, respectively. A small peak appeared at $m / e$ 186. This peak corresponds with ${ }^{64} \mathrm{Zn}$ picolinate. The corresponding ${ }^{66} \mathrm{Zn}$ peak was not detectable. The peak at $\mathrm{m} /$ $e 122$ resulted from the free ligand, picolinic acid. Loss of $\mathrm{CO}_{2}$ from picolinic acid resulted in the peak at $m / e 78$ and the subsequent loss of $\mathrm{HCN}$ generated the peak at $m / e 51$.

The fragmentation mode of a zinc-picolinic acid complex differs from that of the uncomplexed ligand. The mass spectra of picolinic acid and other pyridine carboxylic acids contain minor fragmentation peaks at $m / e 55$ and $m / e 70$ (13). These peaks were quite prominent in the spectra of both the zinc-binding ligand and a preparation of zinc-picolinic acid (Fig 5).

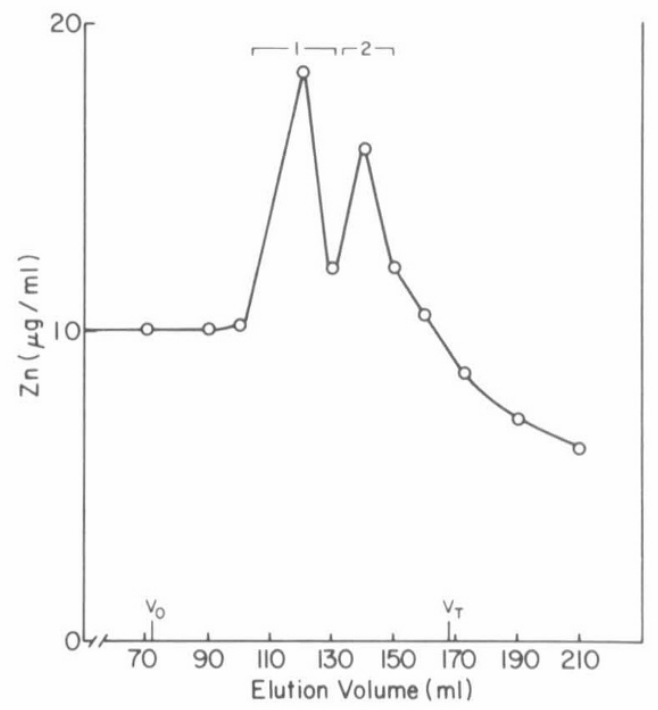

Fig. 4. Chromatography of the zinc-binding ligand from human milk on Sephadex G-15 equilibrated with $\mathrm{Zn}\left(\mathrm{NO}_{3}\right)_{2}$. One g of ultrafiltrate from UM 10 membrane was chromatographed on Dowex 50. Fraction 1 from Dowex 50 (see Fig. 2) was then chromatographed on Dowex 1. Fraction 2 from Dowex 1 (see Fig. 2) was then chromatographed on a $1.6 \times 110-\mathrm{cm}$ column of Sephadex G-15 equilibrated with $0.153 \mathrm{mM} \mathrm{Zn}\left(\mathrm{NO}_{3}\right)_{2}$. Flow rate $=0.25 \mathrm{ml} / \mathrm{min}$ 

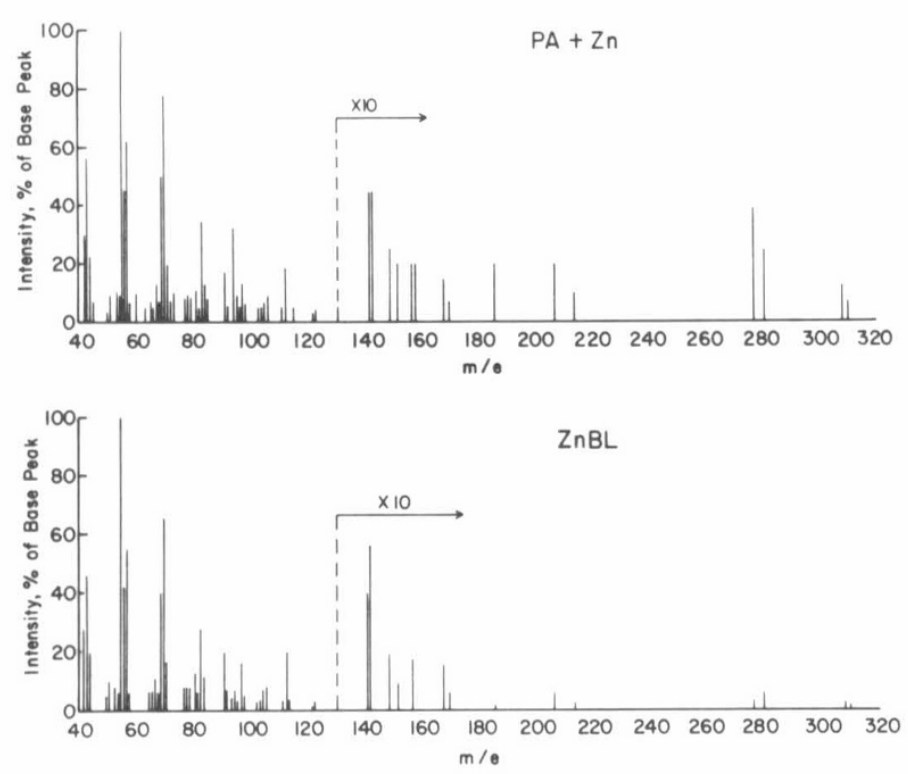

Fig. 5. Mass spectra of the zinc-binding ligand from human milk and of a picolinic acid-zinc complex. The picolinic acid:zinc complex was formed by mixing equimolar quantities of picolinic acid and $\mathrm{Zn}\left(\mathrm{NO}_{3}\right)_{2}$. The solution was adjusted to $\mathrm{pH} 7.0$ with $\mathrm{LiOH}$, incubated at room temperature for $30 \mathrm{~min}$, and thereafter freeze-dried. The spectrum illustrated for the zinc-binding ligand $(\mathrm{ZnBL})$ is that obtained with Fraction 1 recovered from Sephadex G-15 (see Fig. 4).

Table 1. Thin-layer chromatography of the purified zinc-binding ligand and various pyridine carboxylic acids

\section{$R_{\mathrm{f}}$ values}

\begin{tabular}{lccc} 
& \multicolumn{3}{c}{$\mathrm{R}_{\mathrm{f}}$ values } \\
\cline { 2 - 4 } \multicolumn{1}{c}{ Sample } & $\begin{array}{c}\text { Butanol satu- } \\
\text { Butanol:acetic } \\
\text { acid: } \mathrm{H}_{2} \mathrm{O}(4: 1: 2)\end{array}$ & $\begin{array}{c}\text { rated with 2.5 M } \\
\mathrm{NH}_{4} \mathrm{OH}\end{array}$ & $\begin{array}{c}\text { Isopropanol } \\
(80 \%)\end{array}$ \\
\hline Quinolinic acid $^{1}$ & 0.16 & 0.03 & 0.28 \\
Nicotinic acid $^{1}$ & 0.69 & 0.49 & 0.63 \\
Picolinic acid $^{1}$ & 0.40 & 0.34 & 0.40 \\
Picolinic acid $^{\text {zinc }}$ & 0.40 & 0.27 & 0.40 \\
Fraction 1 $^{3}$ & & & \\
Fraction 2 $^{3}$ & 0.40 & 0.27 & 0.40 \\
\hline
\end{tabular}

${ }^{1}$ Sigma Chemical Co., St. Louis, MO.

${ }^{2}$ Equimolar ratio of picolinic acid and $\mathrm{Zn}\left(\mathrm{NO}_{3}\right)_{2}$ adjusted to $\mathrm{pH} 7.0$ with $\mathrm{LiOH}$.

${ }^{3}$ Purified fractions from Sephadex G-15; see Figure 4.

\section{THIN-LAYER CHROMATOGRAPHY}

Analysis of Fractions 1 and 2 from Sephadex G-15 by thinlayer chromatography provided further evidence that both of these fractions contained the same zinc-binding ligand (Table 1). Moreover, the migration in three different solvents of the zinc-binding ligand from human milk was identical to that of a mixture of picolinic acid and zinc.

\section{INFRARED SPECTRA}

The infrared spectrum of the zinc-binding ligand from human milk substantiated the fact that this ligand is picolinic acid. The spectra of the zinc-binding ligand from human milk (Fraction 1 off Sephadex G-15) and a picolinic acid-zinc complex were identical. Both spectra contained absorption bands at 3400 broad strong, 3140 strong, 2980 weak, 2860 strong, 1770 weak, 1650 medium, 1600 strong, 1540 strong, 1450 medium, 1380 strong, 1300 weak, 1230 strong, 1050 weak, 490 weak, 860 weak, 750 strong, 690 strong, 660 weak, 510 weak, and 425 weak. These spectra are very similar to those observed by Paul et al. (14) who studied the characteristics of ethyl picolinate-zinc complexes. Thus, the zinc-binding ligand in human milk is pyridine-2-carboxylic acid, commonly known as picolinic acid.

\section{QUANTITATION OF PICOLINIC ACID IN HUMAN AND COW'S MILK}

The $10 \mathrm{ml}$ pooled sample of human milk we assayed contained $3.1 \mu$ moles picolinic acid which is equivalent to a concentration of $38 \mu \mathrm{g} / \mathrm{ml}$ or $310 \mu \mathrm{M}$. The concentration of picolinic acid in one brand of processed cow's milk was only $20 \mu \mathrm{M}$, and the picolinic acid level in a second brand of cow's milk was undetectable. Picolinic acid was undetectable in each of the four formulas assayed.

\section{EFFECT OF PICOLINIC ACID ON ZINC ABSORPTION IN RATS}

The true, total daily absorption of zinc was significantly greater $(P<0.01)$ in rats fed supplemental picolinic acid than in rats fed the unsupplemented diets (Table 2). The rate of weight gain was also significantly greater $(P<0.01)$ when rats were fed supplemental picolinic acid than when the rats were fed unsupplemented diets. As expected, when methionine was added to the caseinbased diet the rate of weight gain was increased. However, the addition of methionine to the diet did not result in a significant increase in total daily zinc absorption.

\section{DISCUSSION}

The identification of picolinic acid as a zinc-binding ligand in human milk was made possible by the use of modified gel filtration chromatography. Although many organic ligands including picolinic acid form very stable complexes with zinc, these complexes also reach equilibrium rapidly and as a result the metal and ligand dissociate during chromatography on ion-exchange resins as well as cross-linked gels equilibrated with low ionic strength buffers (6). Moreover, several organic ligands, including picolinic acid, contain a highly charged ring structure and as a result bind to cross-linked gels (11). Therefore, after each step in purification (ultrafiltration, cation exchange, and anion exchange), the fractions recovered were first chromatographed on a zinc-equilibrated gel to determine if zinc-binding ligands were present. This technique enabled us to separate a zinc-binding ligand from the other components of the milk and eventually we obtained a highly purified preparation of a zinc-picolinic acid complex. Admittedly, if the gels had been equilibrated with iron, copper, or cadmium we might have identified picolinic acid as an iron-, copper-, and cadmium-binding ligand. However, this does not preclude the fact that this method made possible the identification of a strong bidentate chelating ligand which, to our knowledge, has never been identified in human milk.

Picolinic acid is known to be a bidentate chelating ligand (16, 17). Paul et al. (14) as well as Clark and Williams $(2,3)$ have proven that picolinic acid-metal complexes are formed by coordination with the pyridine nitrogen and the carbonyl oxygen on the adjacent carboxylic acid group. The metal chelate formation

Table 2. Zinc absorption in rats fed supplemental picolinic acid

\begin{tabular}{|c|c|c|c|}
\hline \multirow[b]{2}{*}{ Diet } & \multirow[b]{2}{*}{$\begin{array}{c}\text { Wt gain (g/6 } \\
\text { wk) }\end{array}$} & \multicolumn{2}{|c|}{ Zinc absorption $^{1}$} \\
\hline & & $\mu \mathrm{g} /$ day & $\begin{array}{c}\% \text { of in- } \\
\text { take }\end{array}$ \\
\hline Basal & $170 \pm 17^{2,3}$ & $133 \pm 33^{3}$ & 51.9 \\
\hline Basal + $\mathbf{P A}^{3}$ & $221 \pm 8^{5}$ & $205 \pm 26^{5}$ & 64.5 \\
\hline Basal + met $^{4}$ & $202 \pm 10^{7}$ & $165 \pm 19^{3}$ & 52.5 \\
\hline $\mathrm{Basal}+\mathrm{met}+\mathrm{PA}$ & $219 \pm 5^{5}$ & $280 \pm 45^{7}$ & 72.0 \\
\hline
\end{tabular}

${ }^{1}$ True daily absorption of zinc determined by isotope dilution (7).

${ }^{2}$ All values are mean \pm S.D. of six rats. Values in the same column not followed by the same superscript (superscripts 3, 5, and 7) are significantly different $(P<0.01)$.

${ }^{3}$ Picolonic acid, $0.2 \mathrm{mg} / \mathrm{g}$ diet.

${ }^{4}$ DL-Methionine, $2.0 \mathrm{mg} / \mathrm{g}$ diet. 
constants for zinc and picolinic acid determined by Suzuki et al. (16) and von Anderegg (17) are respectively: $\log \mathrm{k}_{1}=5.12$ and 5.3; $\log \mathrm{K}_{2}=4.3$ and $4.32 ;$ and $\log \mathrm{K}=9.42$ and 9.63. The concentration of picolinic acid in human milk is approximately $300 \mu \mathrm{M}$ whereas the concentration of zinc in human milk is generally less than $100 \mu \mathrm{M}$ (10). Thus, the probability for the formation of a zinc:picolinic acid complex is high in human milk as well as in the intestinal lumen of infants consuming human milk.

The results obtained when weanling rats were fed diets supplemented with picolinic acid suggest that this ligand complexes with zinc in the mammalian intestine and facilitates zinc absorption. As shown in Table 2, zinc absorption in rats fed a diet supplemented with picolinic acid was significantly greater than that in the rats fed the unsupplemented basal diet. Moreover, rats fed the picolinic acid-supplemented diet gained significantly more weight than did rats fed the unsupplemented diet. Obviously, dietary supplements of picolinic acid are highly effective in improving dietary zinc absorption.

Recently, Krieger and Evans (12) demonstrated that a commonly used pancreatic extract (Viokase; Viobin, Monticello, IL) contains a substantial concentration of picolinic acid. When this pancreatic extract was fed to a female infant, who, after cessation of breast feeding, developed diarrhea, mood changes, and mild rashes, a dramatic improvement was observed. A marked improvement was also observed when the infant was given $45 \mathrm{mg}$ elemental zinc each day without supplemental pancreatic extract. During the period the infant was given the pancreatic extract supplement, the total daily intake of zinc was only $5 \mathrm{mg}$. Therefore, the therapeutic effect of the pancreatic extract is thought to be attributable to the high content of a zinc-binding ligand, picolinic acid, in the extract. Thus, human milk and Viokase, both of which contain picolinic acid, are highly efficacious in improving symptoms related to impaired zinc metabolism.

Whether or not the picolinic acid in human milk is responsible for the increased bioavailability of zinc to infants remains to be determined. As mentioned previously, several clinical observations suggest that the zinc in human milk is more readily absorbed than the zinc from cow's milk and infant formula $(1,4,5,9,15)$. Our results demonstrate that the concentration of picolinic acid in human milk is much higher than that in either cow's milk or infant formulas. Perhaps the higher concentration of picolinic acid in human milk results in the formation of picolinic acid-zinc complexes which are more readily absorbed than ionic zinc or zinc complexed with other ligands.

\section{REFERENCES AND NOTES}

1. Brandt, T.: Dermatitis in children with disturbances of the general condition and the absorption of food elements. Acta Dermato-Venerol., 17: 513 (1936).

2. Clark, R. J. H., and Williams, C. S.: The far-infrared spectra of metal-halide complexes of pyridine and related ligands. Inorg. Chem., 4: 350 (1965).

3. Clark, R. J. H., and Williams, C. S.: Infra-red spectra $\left(3000-200 \mathrm{~cm}^{-1}\right)$ of metalisothiocyanate complexes. Spectrochim. Acta, 22: 1081 (1966).

4. Danbolt, N.: Acrodermatitis enteropathica. Acta Dermato.-Venereol., 28: 532 (1948).

5. Entwisle, B. R.: Acrodermatitis enteropathica. Aust. J. Dermatol., 8: 13 (1965).

6. Evans, G. W., Johnson, P. E., Brushmiller, J. G., and Ames, R. W.: Detection of labile zinc-binding ligands in biological fluids by modified gel filtration chromatography. Anal. Chem., 51: 839 (1979).

7. Evans, G. W., Johnson, E. C., and Johnson, P. E.: Zinc absorption in the rat determined by radioisotope dilution. J. Nutr., 109: 1258 (1979).

8. Hambidge, K. M., Neldner, K. H., Walravens, P. A., Weston, W. L., Silverman, A., Sabol, J. L., and Brown, R. M.: Zinc and acrodermatitis enteropathica, In: K. M. Hambidge, B. L. Nichols, Jr. Zinc and Copper in Clinical Medicine. pp. 81-98, (Spectrum Publications, Inc., Jamaica, N. Y., 1978).

9. Hambidge, K. M., Walravens, P. A., Casey, C. E., Brown, R. M., and Bender, C.: Plasma zinc concentrations of breast-fed infants. J. Pediatr., 94: 607 (1979).

10. Johnson, P. E., and Evans, G. W.: Relative zinc availability in human breast milk, infant formulas, and cow's milk. Am. J. Clin. Nutr., 31: 416 (1978).

11. Kamel, M. Y., and Hamed, R. R.: Chromatographic separation of tryptophan metabolites on a polyamide column. J. Chromatogr., 157: 440 (1978).

12. Krieger, I., and Evans, G. W.: Acrodermatitis enteropathica without hypozincemia. Therapeutic effect of a pancreatic enzyme preparation due to a zinc binding ligand. J. Pediatr., 96: 32 (1980).

13. Moser, R. J., and Brown, E. V.: Mass spectra of some 5- and 6-substituted-2pyridinecarboxylic acids. Nature of fragmentation step for loss of $\mathrm{CO}_{2}$. Organ. Mass Spec., 4: 555 (1970).

14. Paul, R. C., Chopra, R. S., Bhambri, R. K., and Singh, G.: Metal complexes of ethyl picolinate. J. Inorg. Nucl. Chem., 36: 3703 (1974).

15. Schulze, R. R., and Winkelmann, R. K.: Acrodermatitis enteropathica: report of a patient responding to combined therapy with human milk and diiodohydroxyquin. Mayo Clin. Proc., 41: 334 (1966).

16. Suzuki, K., Yasuda, M., and Yamasaki, K.: Stability constants of picolinic and quinaldic acid chelates of bivalent metals. J. Phys. Chem., 61: 229 (1957).

17. von Anderegg, G.: Pyrindinderivate als Komplexbildner I. Pyridincarbonsäuren. Helv. Chim. Acta, 43: 414 (1960).

18. Mention of a trademark or proprietary product does not constitute a guarantee or warranty of the product by the United States Department of Agriculture and does not imply its approval to the exclusion of other products that may also be suitable.

19. The authors thank the women who donated milk for this project and David Miller, Grand Forks Energy Research Center, DOE, for carrying out the mass spectral analysis.

20. Requests for reprints should be addressed to: Dr. Gary W. Evans, Research Chemist, Human Nutrition Center, United States Department of Agriculture, P.O. Box 7166 University Station, Grand Forks, N. D. 58202 (USA).

21. This research was supported in part by USDA Collaborative Agreement No. 12 14-3001-294.

22. Received for publication September 27, 1979.

23. Accepted for publication November 18, 1979. 